\title{
PEMBELAJARAN KOOPERATIF BERBANTUAN ALAT PERAGA UNTUK MENINGKATKAN PEMAHAMAN MATEMATIKA SISWA
}

\author{
Asmidi \\ SMP Negeri 1 Sukadana \\ Email: asmidi100@gmail.com
}

\begin{abstract}
This study is aimed to describe cooperative learning assisted by teaching aids that can improve mathematical understanding of 8th grade students of SMP Negeri 1 Sukadana on cube and beam material. This type of research is classroom action research. The steps of cooperative learning assisted by teaching aids that can improve students' mathematical understanding of cube and beam material are: 1) Conveying goals and preparing students, in this phase the teacher gives apperception and conveys the learning objectives, 2) Presenting information, in this phase the teacher explores students' initial abilities and delivering lesson material 3) Organizing students into learning teams, in this phase the teacher organizes students into heterogeneous learning groups based on student grades and sexes 4) Helping teamwork and learning, in this phase the teacher guides students who have difficulty in completing their group assignments.5) Evaluating, in this phase the teacher gives an individual quiz question. 6) Giving recognition or appreciation, in this phase the teacher gives awards to the group that successfully completes the group task well. Students' understanding of cube and beam material after the application of cooperative learning assisted by teaching aids in this study increased from the "good" category to the "very good" category.
\end{abstract}

Keywords: Cooperative Learning, Understanding of Mathematics

\section{PENDAHULUAN}

Pembelajaran matematika disekolah tidak cukup hanya dengan menekankan siswa untuk menghafal dan mengingat materi matematika, tetapi mereka harus dibekali pemahaman matematika secara mendalam. Secara umum pemahaman matematika terdiri dari pemahaman konseptual dan pemahaman prosedural. Ghazali (2000) menjelaskan bahwa pemahaman matematika konseptual adalah pengetahuan yang melibatkan pemahaman yang menyeluruh tentang konsep dasar dibalik algoritma yang dilakukan dalam matematika. Sedangkan pemahaman matematika prosedural adalah pengetahuan yang berfokus pada keterampilan dan prosedur langkah demi langkah tanpa referensi eksplisit ide-ide matematika.

Pemahaman konsep matematika harus dikuasai dengan baik oleh siswa. Namun pada kenyataannya masih ditemukan masalah terkait pemahaman siswa ketika belajar matematika. Hal ini dapat dilihat dari rendahnya hasil belajar siswa kelas 8 SMP Negeri 1 Sukadana. Rendahnya hasil belajar disebabkan oleh kurangnya pemahaman siswa terhadap konsep dalam menghitung luas permukaan dan volume kubus dan balok. Selain itu aktivitas belajar siswa saat pembelajaran berlangsung masih sangat rendah.

Menyikapi permasalahan diatas, maka perlu adanya pembelajaran yang lebih bermakna bagi siswa. Ausebel dalam (Kilic \& Cakmak, 2013) mengungkapkan bahwa pembelajaran bermakna merupakan salah satu cara yang penting untuk mengubah informasi jangka pendek ke informasi jangka panjang. Salah satu manfaat pembelajaran bermakna dalam belajar matematika adalah terbentuknya pemahaman. Sedangkan pemahaman sendiri sangat penting dalam belajar matematika. Hal ini sejalan dengan Ghazali (2011) yang mengungkapkan bahwa siswa harus memiliki pemahaman yang baik jika mereka ingin memahami matematika secara mendalam.

Agar siswa memiliki pemahaman yang baik maka alat peraga dapat digunakan dalam pembelajaran matematika. hal ini sejalan dengan Pramudjono dalam (Sundayana, 2014) yang mengungkapkan bahwa alat peraga adalah benda konkrit yang dibuat, dihimpun atau disusun secara 
sengaja digunakan untuk membantu menanamkan atau mengembangkan konsep matematika. Penggunaan alat peraga bertujuan agar pembelajaran menjadi aktif dan kreatif dan membantu siswa dalam memahami materi. Oleh karena itu guru harus pandai-pandai dalam memilih alat peraga agar alat peraga tidak menambah kebingungan siswa dalam memahami materi.

Selain membutuhkan pemahaman, belajar matematika juga memerlukan keaktifan siswa. Salah satu cara yang dapat melibatkan aktivitas siswa secara aktif adalah dengan menerapkan model pembelajaran kooperatif. Dalam pembelajaran kooperatif memberikan kesempatan kepada siswa saling berinteraksi dan bekerjasama dalam menguasai materi dan menyelesaikan tugas yang merupakan tanggung jawab seluruh anggota kelompok. Slavin (2005:8) menyatakan bahwa inti dari pembelajaran kooperatif, para siswa akan duduk bersama dalam kelompok yang beranggotakan empat orang untuk menguasai materi yang disampaikan guru. Senada dengan Panlumlers \& Wannapiroon (2014) menyatakan bahwa pembelajaran kooperatif merupakan strategi pembelajaran yang diterapkan untuk mengajar tim kecil dengan setiap siswa memiliki tingkat kemampuan yang berbeda untuk saling bekerjasama dan memiliki tanggungjawab untuk memperoleh prestasi belajar. Selanjutnya Isjoni (2010: 23) menyatakan bahwa metode pembelajaran kooperatif adalah suatu metode untuk mewujudkan kegiatan belajar mengajar yang berpusat pada siswa (student oriented), terutama untuk mengatasi permasalahan yang ditemukan guru dalam mengaktifkan siswa.

Ciri-ciri belajar kooperatif menurut Subanji (2013:160) adalah siswa bekerja dalam kelompok secara kooperatif untuk menuntaskan materi belajarnya; kelompok dibentuk secara hetergogen, berkemampuan tinggi, sedang, dan rendah; kelompok diupayakan terdiri dari ras, budaya, suku, dan jenis kelamin yang berbeda; penghargaan berorientasi pada kelompok dari pada invividu.

Adapun pembelajaran kooperatif terdiri dari 6 (enam) fase seperti yang di ungkap oleh Suprijono (2012:65) yang disajikan pada tabel berikut ini:

Tabel 1. Fase-Fase Pembelajaran Kooperatif

\begin{tabular}{|c|c|}
\hline Fase-Fase & Perilaku Guru \\
\hline $\begin{array}{l}\text { Fase 1: Present goals and set } \\
\text { Menyampaikan tujuan dan mempersiapkan } \\
\text { peserta didik }\end{array}$ & $\begin{array}{l}\text { Menjelaskan tujuan pembelajarandan } \\
\text { mempersiapkan peserta didik siap belajar }\end{array}$ \\
\hline $\begin{array}{l}\text { Fase 2: Present information } \\
\text { Menyajikan informasi }\end{array}$ & $\begin{array}{l}\text { Mempresentasikan informasi kepada peserta } \\
\text { didik secara verbal }\end{array}$ \\
\hline $\begin{array}{l}\text { Fase 3: Organize students into learning teams } \\
\text { Mengorganisir peserta didik ke dalam tim-tim } \\
\text { belajar }\end{array}$ & $\begin{array}{l}\text { Memberikan penjelasan kepada peserta didik } \\
\text { tentang tata cara pembentukan tim belajar dan } \\
\text { membantu kelompok melakukan transisi yang } \\
\text { efisien }\end{array}$ \\
\hline $\begin{array}{l}\text { Fase 4: Assist team work and study } \\
\text { Membantu kerja tim dan belajar }\end{array}$ & $\begin{array}{l}\text { Membantu tim-tim belajar selama peserta } \\
\text { didik mengerjakan tugasnya. }\end{array}$ \\
\hline $\begin{array}{l}\text { Fase 5: Test on the materials } \\
\text { Mengevaluasi }\end{array}$ & $\begin{array}{l}\text { Menguji pengetahuan peserta didik mengenai } \\
\text { berbagai materi pembelajaran atau kelompok- } \\
\text { kelompok mempresentasikan hasil kerjanya }\end{array}$ \\
\hline $\begin{array}{l}\text { Fase 6: Provide recognition } \\
\text { Memberikan pengakuan atau penghargaan }\end{array}$ & $\begin{array}{l}\text { Mempersiapkan cara untuk mengakui usaha } \\
\text { dan prestasi individu maupun kelompok. }\end{array}$ \\
\hline
\end{tabular}

Pembelajaran kooperatif telah menjadi perhatian banyak peneliti seperti (Zakaria \& Iksan, 2006; Ajaja, 2010; Aziz \& Hossain, 2010; Iyer, 2013). Zakaria \& Iksan (2006) menyatakan bahwa pembelajaran kooperatif menciptakan banyak kesempatan belajar yang tidak biasanya terjadi di kelas tradisional. Ajaja (2010) menyatakan bahwa dalam kelompok pembelajaran kooperatif, siswa secara bertahap bertanggungjawab untuk belajar satu sama lain. Aziz \& Hossain, (2010) 
menyatakan bahwa pembelajaran kooperatif berpengaruh terhadap prestasi belajar matematika siswa. Iyer (2013) menyatakan bahwa pembelajaran kooperatif merupakan alat yang dapat digunakan untuk meningkatkan prestasi siswa di dalam kelas.

Berdasarkan paparan diatas, rumusan masalah dalam penelitian ini adalah "bagaimanakah pembelajaran kooperatif berbantuan alat peraga yang dapat meningkatkan pemahaman matematika siswa kelas 8 SMP Negeri 1 Sukadana pada materi kubus dan balok?". Berdasarkan rumusan masalah, maka penelitian ini bertujuan untuk mendeskripsikan pembelajaran kooperatif berbantuan alat peraga yang dapat meningkatkan pemahaman matematika siswa kelas 8 SMP Negeri 1 Sukadana pada materi kubus dan balok.

Dalam penelitian ini, manfaat yang diharapkan adalah agar siswa dapat membuka diri untuk saling berdiskusi dan bekerja sama dalam memahami materi dengan bantuan alat peraga kubus dan balok, dapat menjadi salah satu pilihan pembelajaran yang dapat diterapkan untuk meningkatkan pemahaman matematika siswa, dan memberikan gambaran untuk dapat dijadikan sebagai bahan evaluasi diri sekolah.

\section{METODE PENELITIAN}

Penelitian ini menggunakan pendekatan kualitatif karena peneliti menjadi instrumen utama dalam penelitian ini karena peneliti sendiri yang merancang, merencanakan, melaksanakan, mengumpulkan, menganalisis, menarik kesimpulan, dan membuat laporan. Adapun jenis penelitian ini adalah penelitian tindakan kelas (classroom action research) karena penelitian dilakukan dikelas untuk meningkatkan kualitas pembelajaran.

Penelitian ini dilaksanakan di SMP Negeri 1 Sukadana. Lokasi ini dipilih karena peneliti merupakan guru matematika di sekolah tersebut. Partisipan penelitian ini adalah 31 siswa kelas VIII/F SMP Negeri 1 Sukadana. Pemilihan partisipan didasarkan pada hasil identifikasi masalah yang dilakukan berdasarkan pengalaman peneliti.

Rancangan penelitian tindakan ini mengacu pada model yang dikembangkan oleh Kemmis dan Taggart yang terdiri dari empat komponen tindakan yakni, perencanaan, tindakan, observasi, dan refleksi. Selanjutnya diagram alir rancangan penelitian diadaptasi dari siklus penelitian tindakan yang dikembangkan oleh Kemmis dan Taggart sebagai berikut:

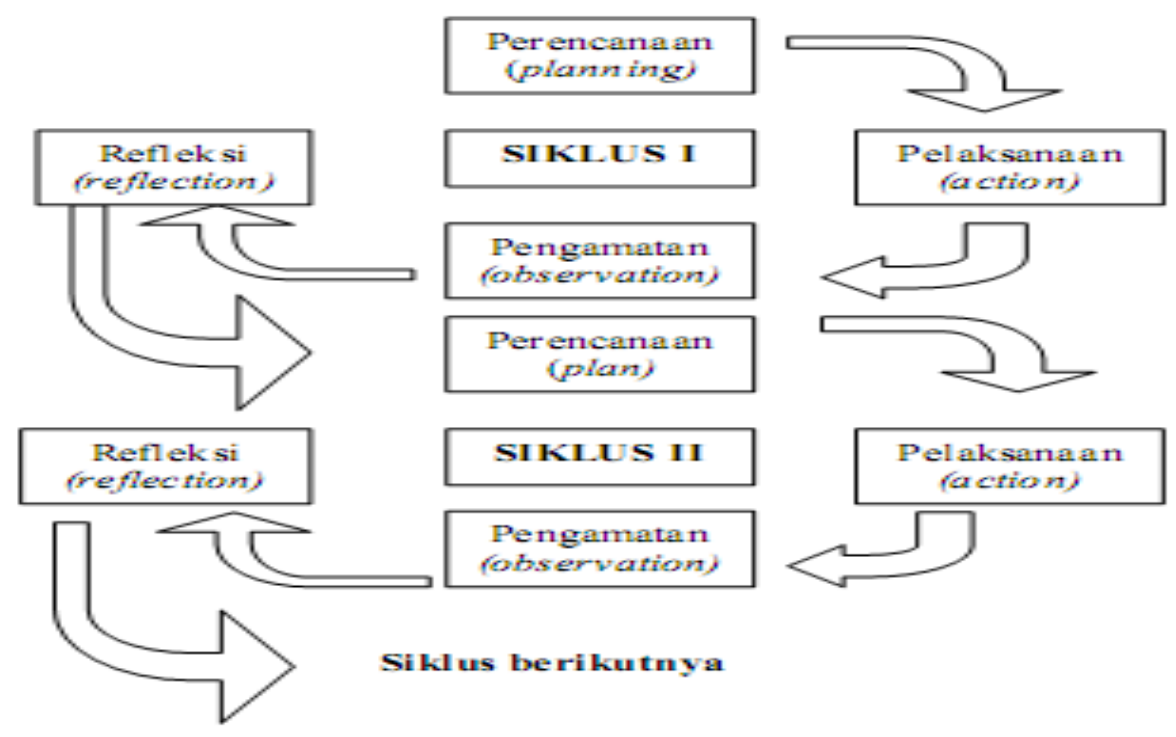

Gambar 1. Siklus Penelitian Tindakan Kelas 
Tahapan-tahan dalam penelitian ini adalah: 1) observasi awal, pada tahap ini, peneliti melakukan analisis hasil belajar siswa, mengamati suasana dan kondisi belajar siswa, dan melakukan tanya jawab kepada siswa untuk mengetahui motivasinya dalam mengikuti belajar matematika., 2) perencanaan tindakan, Pada tahap ini, peneliti akan mengidentifikasi masalah, mengkaji teori-teori yang relevan, serta merumuskan masalah penelitian berdasarkan kajian hasil observasi awal. Selanjutnya merencanakan tindakan dengan merancang: a) rencana pelaksanaan pembelajaran (RPP), b) lembar kerja (LK), c) menyiapkan penilaian tes akhir siklus. Selanjutnya peneliti merencanakan tindakan dengan membuat rencana pelaksanaan pembelajaran (RPP), lembar kerja (LK), dan tes akhir siklus, 3) pelaksanaan tindakan, pada tahap ini, peneliti akan melaksanakan pembelajaran sesuai dengan rencana yang telah disusun pada tahap perencanaan.

Data yang dikumpulkan pada penelitian ini berupa hasil tes akhir siklus siswa. Tes akhir siklus siswa dalam penelitian ini diberikan kepada siswa setiap akhir siklus. Penelitian ini dikatakan berhasil jika kategori pemahaman siswa sudah meningkat. Terdapat peningkatan kategori apabila pemahaman siswa meningkat dari suatu kategori ke kategori di atasnya. Misalnya dari kategori tidak baik menjadi kurang baik atau di atasnya, dari kurang baik menjadi kategori cukup baik atau di atasnya, dan seterusnya.

Proses analisis dilakukan dari awal hingga akhir penelitian dengan tahapan-tahapan 1) reduksi data adalah kegiatan menyeleksi, memfokuskan, dan menyederhanakan semua data mentah dan kasar yang diperoleh. Reduksi dapat dilakukan dengan memilih, menyederhanakan, menggolongkan sekaligus menyeleksi informasi yang relevan dengan masalah penelitian. Hal ini dilakukan untuk memperoleh informasi yang jelas sehingga peneliti dapat menarik kesimpulan yang dapat dipertanggungjawabkan. Pada tahap ini dilakukan penyederhanaan terhadap data yang terkumpul, meliputi hasil tes akhir siklus siswa. 2) penyajian data adalah kegiatan menyajikan hasil reduksi data. Data yang telah disajikan tersebut selanjutnya dibuat penafsiran dan evaluasi untuk tindakan selanjutnya. Hasil penafsiran dan evaluasi dapat berupa hasil tes akhir siklus siswa. 3) penarikan kesimpulan adalah memberikan simpulan terhadap hasil penafsiran dan evaluasi. Pada tahap ini dilakukan pengambilan kesimpulan dari sajian data yang telah diperoleh dalam bentuk kalimat.

\section{HASIL DAN PEMBAHASAN PENELITIAN Siklus 1}

Pada siklus ke-1 dilakukan 4 kali pertemuan yaitu 3 kali pembelajaran kooperatif berbantuan alat peraga dan 1 kali tes akhir siklus. Alokasi waktu untuk 1 kali pertemuan adalah 2 x 40 menit. Materi pembelajaran kooperatif berbantuan alat peraga pada pertemuan pertama adalah unsur-unsur kubus dan balok, pertemuan kedua pada materi menemukan rumus dan menghitung luas permukaan kubus, pertemuan ketiga pada materi menemukan rumus dan menghitung luas permukaan balok. Tes akhir siklus ke-1 dilaksanakan pada pertemuan keempat.

Tes akhir siklus ke-1 diikuti oleh 30 siswa dari 31 siswa kelas VIII/F. Adapun hasil tes siswa pada siklus ke-1 disajikan pada tabel berikut ini:

Tabel 2. Hasil Tes Siklus Ke-1

\begin{tabular}{|c|c|c|c|c|c|c|c|}
\hline \multirow{3}{*}{ No } & \multirow{2}{*}{ Siswa } & \multicolumn{3}{|c|}{ Nomor Soal } & \multirow{3}{*}{ Skor } & \multirow{3}{*}{ Persentase } & \multirow{3}{*}{ Kriteria } \\
\hline & & 1 & 2 & 3 & & & \\
\hline & Bobot Soal & 10 & 10 & 10 & & & \\
\hline 1 & AR & 10 & 10 & 10 & 30 & 100 & Sangat Baik \\
\hline 2 & $\mathrm{AA}$ & 10 & 10 & 5 & 25 & 83 & Sangat Baik \\
\hline 3 & $\mathrm{AG}$ & 10 & 10 & 2 & 22 & 73 & Baik \\
\hline 4 & ASP & 10 & 10 & 10 & 30 & 100 & Sangat Baik \\
\hline 5 & $\mathrm{CC}$ & 10 & 10 & 5 & 25 & 83 & Sangat Baik \\
\hline 6 & DAS & 10 & 10 & 5 & 25 & 83 & Sangat Baik \\
\hline
\end{tabular}




\begin{tabular}{lccccccc}
\hline 7 & DH & 10 & 10 & 6 & 26 & 87 & Sangat Baik \\
\hline 8 & ES & 10 & 5 & 2 & 17 & 57 & Cukup Baik \\
\hline 9 & ELS & 10 & 2 & 2 & 14 & 47 & Cukup Baik \\
\hline 10 & FRK & 10 & 10 & 5 & 25 & 83 & Sangat Baik \\
\hline 11 & FY & 10 & 2 & 2 & 14 & 47 & Cukup Baik \\
\hline 12 & HGA & 5 & 10 & 5 & 20 & 67 & Baik \\
\hline 13 & HAP & 5 & 4 & 10 & 19 & 63 & Baik \\
\hline 14 & HTD & 10 & 10 & 10 & 30 & 100 & Sangat Baik \\
\hline 15 & IFM & 10 & 10 & 10 & 30 & 100 & Sangat Baik \\
\hline 16 & IF & 10 & 2 & 2 & 14 & 47 & Cukup Baik \\
\hline 17 & NS & 10 & 2 & 2 & 14 & 47 & Cukup Baik \\
\hline 18 & NVS & 10 & 5 & 10 & 25 & 83 & Sangat Baik \\
Sambungan Tabel 2 & & & & & & \\
\hline No & Siswa & Nomor Soal & Skor & Persentase & Kriteria \\
\hline \multicolumn{1}{l}{} & & 1 & & & 2 & 3 & \\
\hline 20 & NRW & 10 & 10 & 10 & 30 & 100 & Sangat Baik \\
\hline 21 & RA & 10 & 0 & 2 & 12 & 40 & Kurang Baik \\
\hline 22 & RA & 10 & 10 & 10 & 30 & 100 & Sangat Baik \\
\hline 23 & RS & 10 & 5 & 6 & 21 & 70 & Baik \\
\hline 24 & SFH & 10 & 10 & 9 & 29 & 97 & Sangat Baik \\
\hline 25 & STZ & 10 & 2 & 2 & 14 & 47 & Cukup Baik \\
\hline 26 & SG & 10 & 10 & 10 & 30 & 100 & Sangat Baik \\
\hline 27 & SP & 10 & 2 & 2 & 14 & 47 & Cukup Baik \\
\hline 28 & SR & 10 & 10 & 10 & 30 & 100 & Sangat Baik \\
\hline 29 & SAF & 10 & 10 & 10 & 30 & 100 & Sangat Baik \\
\hline 30 & TVA & 10 & 10 & 10 & 30 & 100 & Sangat Baik \\
\hline & TL & 10 & 10 & 10 & 30 & 100 & Sangat Baik \\
\hline & Rata-rata & & & & & 78 & Baik \\
\hline
\end{tabular}

Berdasarkan tabel diatas, hasil tes akhir tindakan siklus ke-1 yang berupa skor kemampuan pemahaman siswa adalah $4 \%$ siswa termasuk kategori "kurang baik", 23\% siswa termasuk kategori "cukup baik", 13\% termasuk kategori "baik", dan 60\% siswa termasuk kategori "sangat baik". Hasil analisis skor tes pemahaman siswa sebesar 78 termasuk kategori "baik".
Berdasarkan refleksi yang dilakukan diketahui bahwa masih ada siswa yang belum mampu memahami materi dengan baik. hal ini disebabkan ada siswa yang aktif dan belum bisa memperagakan alat peraga. Adapun kelemahankelemahan yang terjadi pada tindakan siklus ke-1 disajikan dalam tabel berikut.

\section{Tabel 3. Kelemahan Tindakan Siklus ke-1 dan Perbaikan Tindakan Siklus ke-2}

\begin{tabular}{clll}
\hline No & \multicolumn{1}{c}{ Kelemahan } & \multicolumn{1}{c}{ Penyebab } & \multicolumn{1}{c}{ Rencana Perbaikan } \\
\hline 1 & $\begin{array}{l}\text { Masih ada siswa yang } \\
\text { belum mampu } \\
\text { memeragakan alat peraga }\end{array}$ & $\begin{array}{l}\text { Guru hanya terpaku } \\
\text { pada beberapa siswa } \\
\text { yang aktif saja. }\end{array}$ & $\begin{array}{l}\text { Meningkatkan aktivitas siswa } \\
\text { saat mempera-gakan alat peraga. }\end{array}$ \\
\hline 2 & $\begin{array}{l}\text { Diskusi kelompok belum } \\
\text { berjalan secara baik }\end{array}$ & $\begin{array}{l}\text { Siswa belum terbiasa } \\
\text { belajar dengan metode } \\
\text { diskusi. }\end{array}$ & $\begin{array}{l}\text { Meningkatkan kerjasama sesama } \\
\text { siswa. }\end{array}$ \\
\hline
\end{tabular}




\begin{tabular}{|c|c|c|c|}
\hline 3 & $\begin{array}{l}\text { Siswa kurang } \\
\text { mengungkapkan } \\
\text { permasalahan yang } \\
\text { dihadapinya. }\end{array}$ & $\begin{array}{l}\text { Siswa belum terbiasa } \\
\text { untuk mengungkapkan } \\
\text { permasalahannya kepada } \\
\text { guru. }\end{array}$ & $\begin{array}{l}\text { Meningkatkan perhatian pada } \\
\text { siswa yang masih malu } \\
\text { bertanya. }\end{array}$ \\
\hline 4 & $\begin{array}{l}\text { Pembelajaran melebihi } \\
\text { alokasi waktu yang } \\
\text { ditentukan. }\end{array}$ & $\begin{array}{l}\text { Siswa terlalu lama pada } \\
\text { tahap diskusi kelompok } \\
\text { dan mengerjakan soal } \\
\text { pada lembar kerja. }\end{array}$ & $\begin{array}{l}\text { Memberikan penegasan batas } \\
\text { waktu dalam diskusi dan } \\
\text { pengerjaan soal. }\end{array}$ \\
\hline
\end{tabular}

Berdasarkan hasil analisis data yang diuraikan diatas, disimpulkan bahwa tindakan pada siklus ke1 masih banyak terdapat kelemahan sehingga tindakan dilanjutkan ke siklus ke-2 dengan perbaikan terhadap kelemahan-kelemahan yang terjadi pada siklus ke-1.

\section{Siklus 2}

Pada siklus ke-2 dilakukan 3 kali pertemuan yaitu 1 kali pembelajaran kooperatif berbantuan alat peraga dan 1 kali tes akhir siklus. Alokasi waktu untuk 1 kali pertemuan adalah 2 x 40 menit. Materi pembelajaran kooperatif berbantuan alat peraga pada pertemuan pertama adalah menemukan rumus dan menghitung volume kubus, pertemuan kedua adalah menemukan rumus dan menghitung volume balok. Tes akhir siklus ke-2 dilaksanakan pada pertemuan ketiga.

Tes akhir siklus ke-2 diikuti oleh 26 siswa kelas VIII/F. Adapun hasil tes siswa pada siklus ke-2 disajikan pada tabel berikut ini :

\section{Tabel 4. Hasil Tes Siklus Ke-2}

\begin{tabular}{|c|c|c|c|c|c|c|c|}
\hline \multirow{4}{*}{ No } & \multirow[t]{2}{*}{ Siswa } & \multicolumn{3}{|c|}{ Nomor } & \multirow{4}{*}{$\begin{array}{c}\text { Sko } \\
\text { r }\end{array}$} & \multirow{4}{*}{$\begin{array}{c}\text { Persenta } \\
\text { se }\end{array}$} & \multirow{4}{*}{ Kriteria } \\
\hline & & 1 & 2 & 3 & & & \\
\hline & \multirow{2}{*}{ Bobot Soal } & 1 & 1 & 1 & & & \\
\hline & & 0 & 0 & 0 & & & \\
\hline \multirow{2}{*}{1} & \multirow{2}{*}{$\mathrm{AR}$} & 1 & 1 & 1 & 30 & 100 & Sonort Boil \\
\hline & & 0 & 0 & 0 & 30 & 100 & Sangat Balk \\
\hline 2 & AA & $\begin{array}{l}1 \\
0\end{array}$ & 2 & 2 & 14 & 47 & Cukup Baik \\
\hline \multirow{2}{*}{3} & \multirow{2}{*}{ AGA } & \multirow{2}{*}{5} & 1 & 1 & 25 & 83 & Sanoat Baik \\
\hline & & & 0 & 0 & $2 J$ & 03 & Sallgat Dall \\
\hline \multirow{2}{*}{4} & \multirow{2}{*}{ ASP } & 1 & 1 & 1 & 30 & 100 & Sanoat Baik \\
\hline & & 0 & 0 & 0 & 30 & 100 & Sangat Balk \\
\hline \multirow[t]{2}{*}{5} & \multirow{2}{*}{$\mathrm{CC}$} & 1 & 9 & 1 & 29 & 97 & Sangat Baik \\
\hline & & 0 & & 0 & & & \\
\hline \multirow{2}{*}{6} & \multirow{2}{*}{ DAS } & \multirow{2}{*}{5} & 1 & 1 & 25 & 83 & Sangat Raik \\
\hline & & & 0 & 0 & 25 & 83 & Sangat Ba1k \\
\hline \multirow{2}{*}{7} & \multirow{2}{*}{ DH } & \multirow{2}{*}{5} & 1 & 1 & 25 & 83 & Sangat Baik \\
\hline & & & 0 & & & & \\
\hline 8 & $\mathrm{ES}$ & 2 & 9 & 9 & 20 & 67 & Baik \\
\hline \multirow[t]{2}{*}{9} & \multirow{2}{*}{ ELS } & 1 & 1 & 6 & 26 & 87 & Sangat Baik \\
\hline & & 0 & 0 & & & & \\
\hline 10 & FRS & 5 & 9 & $\begin{array}{l}1 \\
0\end{array}$ & 24 & 80 & Baik \\
\hline 11 & HAP & 2 & $\begin{array}{l}1 \\
0\end{array}$ & $\begin{array}{l}1 \\
0\end{array}$ & 22 & 73 & Baik \\
\hline
\end{tabular}




\begin{tabular}{|c|c|c|c|c|c|c|c|}
\hline 12 & HTD & 2 & $\begin{array}{l}1 \\
0\end{array}$ & $\begin{array}{l}1 \\
0\end{array}$ & 22 & 73 & Baik \\
\hline 13 & IFM & $\begin{array}{l}1 \\
0 \\
\end{array}$ & $\begin{array}{l}1 \\
0 \\
\end{array}$ & $\begin{array}{l}1 \\
0 \\
\end{array}$ & 30 & 100 & Sangat Baik \\
\hline 14 & NS & $\begin{array}{l}1 \\
0\end{array}$ & $\begin{array}{l}1 \\
0\end{array}$ & $\begin{array}{l}1 \\
0\end{array}$ & 30 & 100 & Sangat Baik \\
\hline 15 & NVS & $\begin{array}{l}1 \\
0 \\
\end{array}$ & 5 & 2 & 17 & 57 & Cukup Baik \\
\hline 16 & NRW & $\begin{array}{l}1 \\
0\end{array}$ & $\begin{array}{l}1 \\
0 \\
\end{array}$ & $\begin{array}{l}1 \\
0 \\
\end{array}$ & 30 & 100 & Sangat Baik \\
\hline 17 & RDA & $\begin{array}{l}1 \\
0\end{array}$ & 2 & $\begin{array}{l}1 \\
0\end{array}$ & 22 & 73 & Baik \\
\hline 18 & RH & $\begin{array}{l}1 \\
0\end{array}$ & $\begin{array}{l}1 \\
0\end{array}$ & 6 & 26 & 87 & Sangat Baik \\
\hline 19 & $\mathrm{RS}$ & $\begin{array}{l}1 \\
0 \\
\end{array}$ & 5 & 5 & 20 & 67 & Baik \\
\hline 20 & ASI & 5 & $\begin{array}{l}1 \\
0 \\
\end{array}$ & $\begin{array}{l}1 \\
0 \\
\end{array}$ & 25 & 83 & Sangat Baik \\
\hline 21 & STZ & $\begin{array}{l}1 \\
0\end{array}$ & $\begin{array}{l}1 \\
0\end{array}$ & $\begin{array}{l}1 \\
0\end{array}$ & 30 & 100 & Sangat Baik \\
\hline 22 & SP & 5 & 5 & $\begin{array}{l}1 \\
0\end{array}$ & 20 & 67 & Baik \\
\hline 23 & SR & $\begin{array}{l}1 \\
0 \\
\end{array}$ & $\begin{array}{l}1 \\
0\end{array}$ & $\begin{array}{l}1 \\
0\end{array}$ & 30 & 100 & Sangat Baik \\
\hline 24 & SAF & $\begin{array}{l}1 \\
0\end{array}$ & $\begin{array}{l}1 \\
0\end{array}$ & $\begin{array}{l}1 \\
0\end{array}$ & 30 & 100 & Sangat Baik \\
\hline 25 & TVA & 5 & 9 & $\begin{array}{l}1 \\
0\end{array}$ & 24 & 80 & Baik \\
\hline 26 & TL & $\begin{array}{l}1 \\
0\end{array}$ & $\begin{array}{l}1 \\
0\end{array}$ & $\begin{array}{l}1 \\
0\end{array}$ & 30 & 100 & Sangat Baik \\
\hline & Rata-rata & & & & & 84 & Sangat Baik \\
\hline
\end{tabular}

Berdasarkan tabel diatas, hasil tes akhir tindakan siklus ke-2 yang berupa skor pemahaman siswa adalah $0 \%$ siswa termasuk kategori "tidak baik", 0\% siswa termasuk kategori "kurang baik", $8 \%$ siswa termasuk kategori "cukup baik", $31 \%$ termasuk kategori "baik", dan $61 \%$ siswa termasuk kategori "sangat baik". Hasil analisis skor tes pemahaman siswa sebesar 84 termasuk kategori “ sangat baik".

Berdasarkan hasil analisis data yang diuraikan diatas, disimpulkan bahwa tindakan siklus ke-2 sudah memenuhi kriteria keberhasilan yang telah ditetapkan dengan pemahaman siswa termasuk kategori sangat baik, sehingga mengalami peningkatan dari kategori baik pada tindakan siklus ke-1 menjadi kategori sangat baik pada tindakan siklus ke-2.
Adapun langkah-langkah pembelajaran kooperatif berbantuan alat peraga yang dapat meningkatkan pemahaman matematika siswa adalah sebagai berikut :

Menyampaikan tujuan dan mempersiapkan peserta didik. Pada fase ini, peneliti menyampaikan tujuan pembelajaran yang akan dicapai siswa setelah pembelajaran dilaksanakan. Menyampaikan tujuan pembelajaran penting dilakukan agar siswa mengetahui arah yang akan dicapai dalam pembelajaran sehingga siswa akan termotivasi untuk melaksanakan pembelajaran dan akhirnya hasil pembelajaran dapat tercapai secara maksimal. 
Menyajikan informasi. Setelah menyampaikan tujuan pembelajaran, peneliti melakukan tanya jawab untuk mengeksplorasi pengetahuan awal siswa tentang materi yang telah dipelajari sebelumnya sebagai materi prasyarat. Kemudian guru menyampaikan materi pelajaran dengan cara menjelaskan materi pelajaran dan tanya jawab.

Mengorganisir peserta didik ke dalam tim-tim belajar. Setelah menyampaikan informasi, fase selanjutnya adalah membentuk kelompokkelompok belajar. Pembentukan kelompok dalam pembelajaran kooperatif pada materi kubus dan balok dilakukan peneliti dengan mengelompokkan siswa kedalam kelompok-kelompok belajar yang jumlah anggotanya 4 sampai 5 siswa. Kelompok yang dibentuk sifatnya heterogen berdasarkan tingkat kemapuan dan jenis kelamin. Hal ini sesuai dengan ciri-ciri pembelajaran kooperatif yang diungkapkan oleh Subanji (2013) yang menyatakan bahwa kelompok dibentuk secara hetergogen, berkemampuan tinggi, sedang, dan rendah. Kelompok diupayakan terdiri dari ras, budaya, suku, dan jenis kelamin yang berbeda.

Pembentukan kelompok yang bersifat heterogen dalam kooperatif bertujuan untuk memberikan kesempatan kepada siswa untuk belajar secara bersama-sama dalam memahami materi pelajaran. Hal ini sesuai dengan Zakaria \& Iksan (2006) yang menyatakan bahwa pembelajaran kooperatif menciptakan banyak kesempatan belajar yang tidak biasanya terjadi di kelas tradisional. Belajar dalam kelompok kooperatif juga dapat melatih sikap siswa untuk saling bertanggung jawab atas hasil belajarnya dan juga teman-teman dalam kelompoknya. Hal ini sesuai dengan pendapat Ajaja (2010) yang menyatakan bahwa dalam kelompok pembelajaran kooperatif, siswa secara bertahap bertanggungjawab untuk belajar satu sama lain.

Membantu kerja tim dan belajar. Pada fase ini, peneliti memantau dan mengawasi jalannya diskusi siswa dalam menyelesaikan tugas kelompok. Peneliti juga memberikan bimbingan pada kelompok yang mengalami permasalahan dalam meperagakan alat peraga kubus dan balok.

Mengevaluasi. Setelah kegiatan belajar secara kelompok selesai, peneliti melakukan evaluasi dengan meminta siswa untuk mengerjakan soal kuis secara individu. Saat mengerjakan soal kuis siswa dilarang untuk saling bekerjasama dan melihat buku catatan. Hal ini dilakukan agar setiap siswa bertanggung jawab untuk memahami materi pelajaran secara individu. Hasil pekerjaan siswa dalam menyelesaikan soal kuis akan diberi skor untuk menentukan poin peningkatan individu.

Evaluasi sangat penting dilakukan untuk melihat keberhasilan siswa dalam mencapai tujuan pembelajaran yang telah dilaksanakan. Hal ini sejalan dengan Sanjaya (2008:33) yang menyatakan bahwa eavluasi sebagai kegiatan yang bertujuan untuk menilai keberhasilan siswa.

Memberikan pengakuan atau penghargaan. Setelah mengerjakan soal kuis, peneliti memberikan penghargaan kelompok. Penghargaan terhadap kelompok sangat penting diberikan agar siswa termotivasi untuk saling membatu dan bekerjasama dalam memahami materi dan menyelesaikan tugas kelompok sehingga prestasi kelompok akan terus meningkat. Hal ini sejalan dengan Sanjaya (2008:249) yang menyatakan bahwa pengakuan dan pemberian penghargaan dapat memotivasi kelompok untuk terus berprestasi dan juga membangkitkan motivasi kelompok lain untuk lebih mampu meningkatkan prestasi mereka.

\section{KESIMPULAN DAN SARAN Kesimpulan}

Berdasarkan paparan data hasil penelitian, hasil analisis data dan pembahasan dapat disimpulkan bahwa langkah-langkah pembelajaran kooperatif berbantuan alat peraga untuk meningkatkan pemahaman matematika siswa pada materi kubus dan balok adalah sebagai berikut: 1) menyampaikan tujuan dan mempersiapkan peserta didik, pada fase ini guru memberikan apersepsi dan menyampaikan tujuan pembelajaran 2) menyajikan informasi, pada fase ini guru mengekplorasi kemampuan awal siswa dan menyampaikan materi pelajaran 3) mengorganisir peserta didik ke dalam tim-tim belajar, pada fase ini guru mengorganisasikan siswa kedalam kelompok belajar yang bersifat heterogen berdasarkan nilai dan jenis kelamin siswa 4) membantu kerja tim dan belajar, pada fase ini guru membimbing siswa yang mengalami kesulitan dalam menyelesaikan tugas kelompoknya 5) mengevaluasi, pada fase ini guru 
memberikan soal kuis secara individu 6) memberikan pengakuan atau penghargaan, pada fase ini guru memberikan penghargaan pada kelompok yang berhasil menyelesaikan tugas kelompok dengan baik. Pemahaman siswa pada materi kubus dan balok setelah penerapan pembelajaran kooperatif berbantuan alat peraga pada penelitian ini meningkat dari kategori "baik" menjadi kategori "sangat baik".

\section{Saran}

Beberapa saran yang dapat disampaikan agar pembelajaran kooperatif berbantuan alat peraga dapat meningkatkan pemahaman siswa adalah : materi prasyarat harus dikuasai agar siswa mampu mengkonstruksi pengetahuan baru dalam menyelesaikan tugas kelompok, melatih siswa untuk saling menerima perbedaan pendapat, dan alokasi waktu pada tahapan pembelajaran diatur secara cermat agar pembelajaran berjalan secara efektif.

\section{DAFTAR PUSTAKA}

Ajaja, O.P. 2010. Effects of Cooperative Learning Strategy on Junior Secondary School Students Achievement in Integrated Science. Electronic Journal of Science Education Vol. 14, No. 1.

Aziz, Z \& Hossain, A. 2010. A comparison of cooperative learning and conventional teaching on students' achievement in secondary mathematics. Procedia Social and Behavioral Sciences 9 (2010) 53-62.

Ghazali, N. 2011. Student's Procedural and Conceptual Undertanding of Mathematics. Australian Journal of Basic and Applied Sciences, 5 (7): 684-691.

Isjoni. 2013. Pembelajaran Kooperatif. Yogyakarta: Pustaka Belajar..

Iyer, R.B. 2013. Relation between Cooperative Learning and Student Achievement. International Journal of Education and Information Studies. ISSN 2277-3169 Volume 3, Number 1, pp. 21-25.

Kilic, M. \& Cakmak, M. 2013. Concept Maps as A Tool for Meaningful Learning and Teaching in Chemistry Education. International Journal on New Trends in Education and Their Implications. Volume: 4 Issue: 4.

Panlumlers \& Wannapiroon. 2014. Design of cooperative problem-based learning activities to enhance cooperation skill in online environment. Procedia - Social and Behavioral Sciences 174 ( 2015 ) 2184 - 2190. Sanjaya, Wina. 2013. Strategi Pembelajaran. Jakarta: Kencana Prenandamedia Group.

Slavin R.E. 2005. Cooperative Learning. Bandung : Nusa Media.

Subanji. 2013. Pembelajaran Matematika Kreatif dan Inovatif. Malang. UM Press.

Sundayana. 2014. Media dan Alat Peraga dalam Pembelajaran Matematika. Bandung : Alfabeta.

Suprijono, A. 2012. Cooperative Learning. Yogyakarta: Pustaka Belajar.

Zakaria, E \& Iksan Z. 2007. Promoting Cooperative Learning in Science and Mathematics Education: A Malaysian Perspective. Eurasia Journal of Mathematics, Science \& Technology Education, 3(1), 35-39. (online), (http://files.eric.ed.gov/fulltext/ED496240.pd f) 